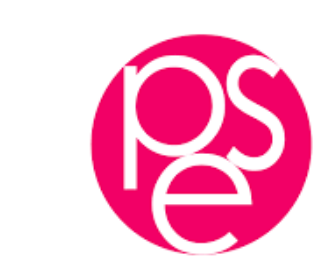

PARISSCHOOLOFECONOMICS
ECOLED'ECONOMIEDEPARIS

WORKING PAPER N ${ }^{\circ} 2020-17$

Feeling good or feeling better?

Alberto Prati

Claudia Senik

JEL Codes: I31, D91

Keywords: life satisfaction; remembered utility, memory biases; intra-personal comparisons.

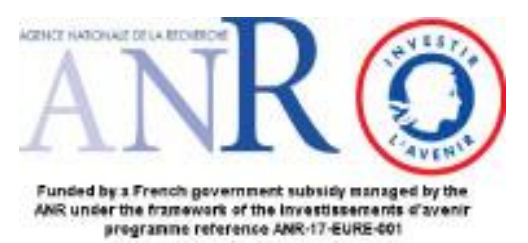




\title{
Feeling good or feeling better?
}

\author{
Alberto Prati ${ }^{\mathrm{a}, *}$, Claudia Senik ${ }^{\mathrm{b}}$ \\ ${ }^{a}$ Aix-Marseille University, CNRS, EHESS, Centrale Marseille, AMSE; France. \\ ${ }^{b}$ Sorbonne-University and Paris School of Economics, France.
}

\begin{abstract}
Can people remember correctly their past well-being? We study three national surveys of the British, German and French population, where more than 50,000 European citizens were asked questions about their current and past life satisfaction. We uncover systematic biases in recalled subjective well-being: on average, people tend to overstate the improvement in their well-being over time and to understate their past happiness. But this aggregate figure hides a deep asymmetry: while happy people recall the evolution of their life to be better than it was, unhappy ones tend to exaggerate its worsening. It thus seems that feeling happy today implies feeling better than yesterday. These results offer an explanation of why happy people are more optimistic, perceive risks to be lower and are more open to new experiences.
\end{abstract}

Keywords: life satisfaction; remembered utility, memory biases; intra-personal comparisons.

JEL: I31, D91

\footnotetext{
*E-mail : alberto.prati@univ-amu.fr. Address: 5, bd Maurice Bourdet - 13001 Marseille (France). We gratefully acknowledge the Investissements d'Avenir Program ANR-17-EURE-0001, ANR-17-EURE-0020 and ANR-16-MYBL-0001-02 grants for financial support. We thank Andrew Clark and Daniela Arlia as well as Stephen Bazen, Gordon Brown, Victor Champonnois, Timothée Demont, Paul Dolan, Sarah Flèche, Paul Frijters, Andrew Oswald and the participants to the seminars at AMSE, Oxford, LSE and Erasmus University for their valuable comments. All errors are our own.
} 


\section{Contents}

1 Introduction 3

2 BHPS: data and variables 5

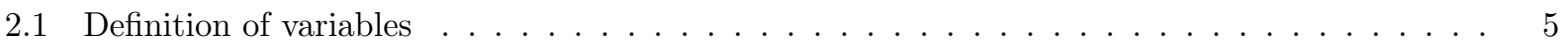

2.2 Descriptive statistics ... . . . . . . . . . . . . . . . . . . . . . 5

3 Stylized facts 8

3.1 Average patterns in misreporting . . . . . . . . . . . . . . . . . 8

3.2 Misreporting and current well-being . . . . . . . . . . . . . . . . . 8

3.3 A matter of scale? . . . . . . . . . . . . . . . . . . . . . . . . . 11

4 Regression analysis 12

4.1 A model of imperfect recall . . . . . . . . . . . . . . . . . . . . . . . 13

4.2 Cross-sectional regression analysis . . . . . . . . . . . . . . . . . . . . . . . 14

4.3 Panel regression analysis . . . . . . . . . . . . . . . . . . . . . . . 15

5 Beyond BHPS: the anatomy of recalled happiness 20

5.1 Self-declared past happiness . . . . . . . . . . . . . . . . . . . . . . 20

5.2 People have biased recall of both recent and remote happiness . . . . . . . . . . . . . . . 22

5.3 People remember correctly the global evolution of their happiness . . . . . . . . . . . . . 23

6 Conclusions 20

7 Appendix 28 


\section{Introduction}

Memory biases create misleading pieces of information that are used for decision-making. When maximizing utility (or well-being), people have to choose between several alternatives, the value of which they often evaluate, when it is possible, based on their memory of the utility they derived in past similar experience. In sum, if expectations are partly based on memory, remembered utility is of importance. So, how reliable is the memory of past utility?

This question was first addressed, empirically, by Daniel Kahneman and colleagues, who uncovered a particular structure of memory biases (Kahneman et al., 1993). Their Peak-End Theory suggested that, within a given episode, people only remember the moment of highest intensity - whether positive or negative and the end of the sequence, but totally neglect the duration of the episode. In particular, having experienced unpleasant episodes (keeping their hand in very cold water), people would remember the longer one as more pleasant, provided it contained an additional less painful moment at the very end (progressively heated water).

Richard Easterlin suggested another type of bias in recalled well-being (Easterlin, 2001). In his view, the memory of past well-being was distorted by people's current situation. This is because, as people adapt to a new situation, they adjust their level of expectations and reevaluate their view of the past in the light of their new benchmark. As concerns income satisfaction for instance: "[People] project current aspirations to be the same throughout the life cycle, while income grows. But since aspirations actually grow along with income, experienced happiness is systematically different from projected happiness. Consequently, choices turn out to be based on false expectations". Hence, "... people typically think that they were worse off in the past and will be better off in the future" (Easterlin, 2001, p.465).

The divergence between remembered utility and experienced utility (Kahneman et al., 1997) bears consequences inasmuch as people's decision utility is based on remembered utility (instead of experienced utility). As the authors themselves say: "The only utility that people (and other organisms) can learn from personal experience to maximize is the utility that they remember. If a retrospective evaluation distorts the hedonic quality of an experience, subsequent preferences will be governed by the biased evaluation, not by the original experience" (Kahneman et al., 1997, p.385-386). In sum, understanding how people take decisions requires understanding how people remember their past utility.

Past satisfaction has received little attention from scholars so far, apart from the small empirical literature dedicated to hedonic adaptation (Clark, 1999; Wilson and Ross, 2000; Van Praag and Ferrer-i Carbonell, 2004; Senik, 2009; Steffel and Oppenheimer, 2009). A few methodological papers have used recalled subjective well-being to assess the test-retest reliability of life satisfaction scores (Atkinson, 1982; Michalos and Kahlke, 2010). They find that recalled evolution is imperfect but statistically consistent with the observed variations. Yet, these studies are silent about memory errors: are they random, in which circumstances do they happen, 
and why?

This paper analyzes the structure of memory biases concerning past well-being. It takes the opportunity of three large longitudinal surveys containing self-assessed life satisfaction judgements and compares people's actual past and current life satisfaction with their subjective evaluation of this evolution over time. It turns out that people display systematic and structured biases in remembered utility. On average, respondents tend to overstate the improvement in their well-being over time. But this average behavior dissimulates an important asymmetry: more cautious scrutiny reveals that happy people tend to overstate the time improvement in their life satisfaction (dynamic overestimation bias), whereas unhappy people tend to overstate the decline in their life satisfaction (dynamic underestimation bias). Because the average level of life satisfaction in the population is fairly high ( 7 on a $0-10$ scale, or 5 on a 1-7 scale), on average, the overestimation bias tends to dominate the underestimation bias. This misperception structure bears important consequences. In particular, it could create a self-reinforcing divergence between happy and unhappy people. Indeed, if happy people tend to think that they were less happy in the past, they will tend to be less conservative and more open to innovation. By contrast, if unhappy people believe that they used to be happier in the past, they could be tempted to try to go back to this past situation, hence be more attached to the statu quo ante. This could constitute a new and additional explanation of the reason why happy people are more optimistic (Foster et al., 2012), perceive risks to be lower (Johnson and Tversky, 1983) and are more open to new experience (Furnham and Petrides, 2003), while unhappy people are more pessimistic, reluctant to change and perceive higher risk.

The remainder of the paper is organized as follows. The next section describes our main data set, the British Household Panel Survey. Based on simple descriptive statistics, section 3 documents the three above-mentioned stylized facts and shows that they cannot be solely explained by features of the satisfaction scale. Section 4 details the results using regression analysis. In section 5 , we move on to the analysis of two representative surveys of the German and French populations to test the assumptions and predictions of our model. Section 6 concludes. 


\section{BHPS: data and variables}

Our main data set is the British Household Panel Survey (BHPS), waves 6-18. The question on general life satisfaction appears in waves 6-10 and 12-18, therefore we can compute first-difference variables for waves 7-10 and 13-18. We remove 787 individuals who display no within-variation along the panel and report satisfaction at the boundaries (they persistently report $L S=1$ or $L S=7$ ). We end up with 111,894 individual-year observations, from 20,269 respondents.

\subsection{Definition of variables}

When using this dataset, we base our analysis on the following variables of interest:

- $L S_{i t}=$ Current life satisfaction, as reported by individual $i$ at time $t$. It is drawn from the question "How dissatisfied or satisfied are you with your life overall?" The response scale varies from 1 ("not satisfied at all") to 7 ("completely satisfied"). It is worth noting that, in contrast to the General Social Survey, the World Value Survey, the European Social Survey and the European Quality of Life Survey, BHPS does not include a temporal frame ("these days", "nowadays", etc.) in the question on life satisfaction.

- $L S_{i t-1}=$ Life satisfaction, as reported by individual $i$ the previous year, i.e. in the previous wave of the survey.

- $\Delta L S_{i t-1}=L S_{i t}-L S_{i t-1}=$ Observed change in life satisfaction.

- $\Delta \widetilde{L S}_{i t-1}=$ Reported change in life satisfaction. It is the answer to the question: "Would you say that you are more satisfied with life, less satisfied or feel about the same as you did a year ago ?". In the survey, the question comes right after the one about general life satisfaction. Possible answers are "more satisfied", "less satisfied", "about the same", "don’t know".

- $E R R_{i t-1}=\Delta \widetilde{L S}_{i t-1}-\Delta L S_{i t-1}=$ Discrepancy between observed and (self-declared) recalled change in life satisfaction. We can only infer the sign of $E R R_{i t-1}$ : positive if $\Delta \widetilde{L S}_{i t-1}>0$ and $\Delta L S_{i t-1} \leq 0$; null if $\Delta \widetilde{L S}_{i t-1}=\Delta L S_{i t-1}$; negative if $\Delta \widetilde{L S}_{i t-1}<0$ and $\Delta L S_{i t-1} \geq 0$.

- We refer to $i$ as misreporting at time $t$ when $\Delta \widetilde{L S}_{i t-1} \neq \Delta L S_{i t-1}$.

\subsection{Descriptive statistics}

Below we summarize some characteristics of the sample:

Average life satisfaction is relatively high, 5.19 out of 7 . Most people report to be as satisfied as in the previous year. However, there is an asymmetry between reported changes: the share of answers reporting a positive evolution is higher than the share of answers reporting a negative evolution. 
Table 1: Summary statistics. $N=111,894$

\begin{tabular}{lccccc}
\hline \hline & mean & se & sd & $\min$ & $\max$ \\
\hline self-declared life satisfaction & 5.19 & $<0.01$ & 1.25 & 1 & 7 \\
"more satisfied than a year ago"? & 0.25 & $<0.01$ & 0.44 & 0 & 1 \\
"about the same as a year ago"? & 0.58 & $<0.01$ & 0.49 & 0 & 1 \\
"less satisfied than a year ago"? & 0.16 & $<0.01$ & 0.36 & 0 & 1 \\
female & 0.53 & $<0.01$ & 0.50 & 0 & 1 \\
age & 48.40 & 0.07 & 17.92 & 16 & 100 \\
monthly household income $(£)$ & 2,722 & 8.83 & 2,126 & 0 & 86,703 \\
\hline \hline
\end{tabular}

Reading note: The estimated mean life satisfaction in the sample is 5.19. The standard error of the survey-weight estimated mean is smaller than 0.01. The empirical standard deviation of the distribution is 1.25, with values ranging from 1 to $\%$

We start our analysis by comparing reported and observed changes in life satisfaction. We can distinguish 9 cases, displayed in Table 2.

Table 2: Cases of reporting behaviors. $N=111,894$

\begin{tabular}{|c|c|c|c|c|c|}
\hline & \multicolumn{3}{|c|}{ Observed } & \\
\hline & & - & $=$ & + & \\
\hline \multirow{3}{*}{ 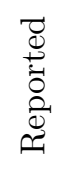 } & - & $8.3 \%$ & $5.4 \%$ & $2.8 \%$ & $16.5 \%$ \\
\hline & $=$ & $15.0 \%$ & $28.5 \%$ & $14.7 \%$ & $58.2 \%$ \\
\hline & + & $4.4 \%$ & $12.1 \%$ & $8.8 \%$ & $25.3 \%$ \\
\hline & & $27.7 \%$ & $46.0 \%$ & $26.3 \%$ & $100 \%$ \\
\hline
\end{tabular}

Reading note: The data set contains 111,894 individual-year points. $8.3 \%$ answers report a negative change in life satisfaction which is consistent with what we observe. Overall, $27.7 \%$ of observed changes are negative and $16.5 \%$ of reported changes are negative.

For the sake of guidance over our analysis, we classify reporting behaviors in four broad types, depending on $\Delta \widetilde{L S}_{i t-1}$ and $E R R_{i t-1} \cdot{ }^{1}$ Observations along the main diagonal of table 2 are cases of correct-reporting: reported and observed changes are the same, so that $E R R=0$. We define as over-reporting instances where people report to be more satisfied than last year, but we do not observe such a change. Symmetrically, we define as under-reporting instances where people report an unobserved negative change. Finally, people can report to be as satisfied as last year while instead we observe a difference between $L S_{i t}$ and $L S_{i t-1}$ : we refer

\footnotetext{
${ }^{1}$ The same individual can display different behaviors along the panel but he/she displays only one reporting behavior per year.
} 
to them as cases of insensitive-reporting. Table 3 summarizes the four types of reporting behaviors.

Table 3: Types of reporting behaviors

\begin{tabular}{cccl}
\hline$\Delta \widetilde{L S}{ }_{i t-1}$ & $E R R_{i t-1}$ & Type & Description \\
\hline,$+=,-$ & $=0$ & correct-reporting & $\begin{array}{l}\text { Report an evolution of life satisfaction that is consistent } \\
\text { with what we observe }\end{array}$ \\
+ & $\neq 0$ & over-reporting & $\begin{array}{l}\text { Report a positive change in life satisfaction that we do not } \\
\text { observe }\end{array}$ \\
& $\neq 0$ & insensitive-reporting & Report no change in life satisfaction but we observe one \\
& $\neq 0$ & under-reporting & Report a negative change in life satisfaction that we do not \\
& & & observe \\
& &
\end{tabular}




\section{Stylized facts}

In this section we use simple descriptive statistics to show the existence of three stylized facts, related to the dynamic of recalled well-being. We start by looking at the relationship between observed and reported changes in well-being, after which we consider this relationship in light of current well-being.

\subsection{Average patterns in misreporting}

Table 2 suggests that people are, to some extent, able to recall the evolution of their well-being. If reported changes $\Delta \widetilde{L S}_{i t-1}$ were uncorrelated to observed changes $\left(\Delta L S_{i t-1}\right)$, the nine cells of the table would display similar percentages. Instead, when we observe an increase in the life satisfaction score $(26.7 \%$ of the total), people report a positive evolution three times more often than a negative one (9.3\% vs $2.7 \%)$; situations where we observe a decrease in the life satisfaction score (28.2\% of the total) are reported twice more often as negative than positive ( $8.1 \%$ vs $4.8 \%)$. When no change is observed ( $45.1 \%$ of the total), more than half of the sample reports to be as satisfied as in the previous year.

Nevertheless, the table also shows that differences between observed and reported changes are far from being rare. Overall, correct-reporters represent a little bit less than half of the sample. The rest are cases of misreporting: reported changes do not correspond to observed changes, so that $E R R \neq 0$. Along the panel, over $90 \%$ of respondents misreport at least once. The widespread differences between reported and observed changes represent our first stylized fact:

Stylized fact \#1: Most people report an evolution of life satisfaction that is different from the one observed over time in the panel.

A quick glance tells us that cases of over-reporting are much more common than cases of under-reporting (17.3\% vs $7.7 \%)$, leading us to the formulation of a second stylized fact:

Stylized fact \#2: On average, people tend to overstate the improvement in their life satisfaction over time.

\subsection{Misreporting and current well-being}

To explore the relationship between reporting behaviors and the current level of satisfaction, we now look at the two sides of the conditional correlations: is average life satisfaction equal across groups displaying different reporting behaviors? Are we equally likely to observe under- or over-reporting conditional on different levels of current life satisfaction?

We start with a simple analysis of the first cross-section of the BHPS (wave 7 ) that includes the question "Would you say that you are more satisfied with life, less satisfied or feel about the same as you did a year 
ago ?". Two opposite patterns appear (see fig.1a): over-reporters score significantly higher in life satisfaction than the rest of the population; conversely, under-reporters' life satisfaction is significantly lower than for the rest of the population. There is no significant difference between correct-reporters and insensitive-reporters.

Figure 1: Subjective and objective well-being, by reporting behavior, wave 7

(a) Mean life satisfaction

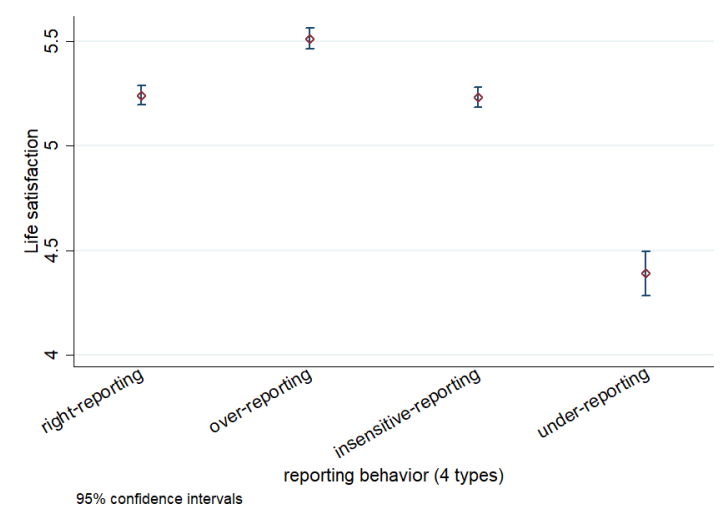

(b) Mean income variation

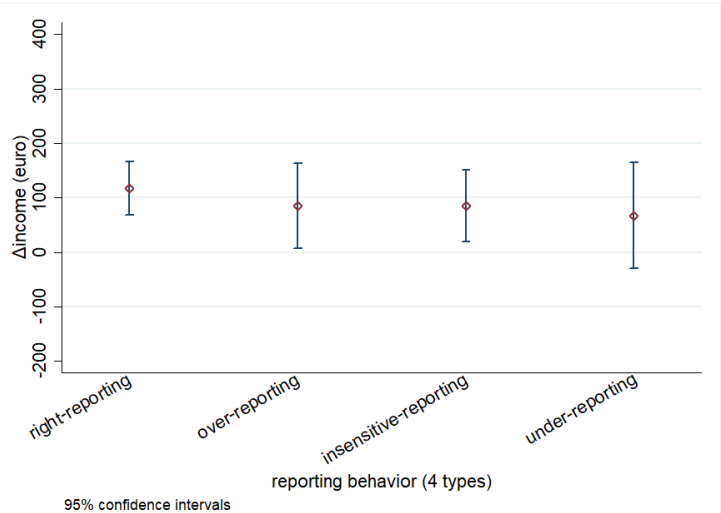

Reading note: According to Figure (a), in wave 7 of the BHPS, 5.2 is the average life satisfaction of people reporting a change in subjective well-being that is consistent with what is observed in waves 6 and 7 . According to Figure (b), 100€ is the average income variation of people reporting a change in subjective well-being that is consistent with what is observed in waves 6 and 7 . Vertical bars are $95 \%$ confidence intervals.

It is worth noting two points. Firstly, the asymmetry in Figure (1a) is not mechanical. Quite the opposite, one would expect over-reporters to be relatively less happy, and under-reporters to be relatively happier. Secondly, this asymmetry does not follow from individual variations in material conditions. As shown by Figure 1b, it is not because they experienced an income rise that over-reporters are happier. Hence, contrary to Easterlin (2001)'s conjecture, the overall tendency to increase personal income over the life cycle cannot explain why people tend to think to be better off than before. ${ }^{2}$

We now move on to the dynamic panel dimension and study misreporting behaviors conditional on life satisfaction scores. We start by looking at people who declare the same life satisfaction level in $t-1$ and $t$, but who report to be more/less satisfied in $t$ than in $t-1$. In this specific case, we can observe only two reporting behaviors: over-reporting or under-reporting. ${ }^{3}$ When we sketch the frequency of under- and over-reporting conditional on $L S_{i t}$, two clear patterns appear (Figure2a):

\footnotetext{
${ }^{2}$ Properly speaking, Easterlin's theory applies to adaptation over the long run, not over one year. In his paper, he explicitly states that he is "talking here of comparisons over periods of some length, say, five years or more, not very short intervals such as year or less" (p.471).

${ }^{3}$ Insensitive-reporting cannot happen when $L S_{i t}=L S_{i t-1}$. Correct-reporting cannot happen when $\Delta \widetilde{L S} S_{i t-1} \neq \Delta L S_{i t-1}$
} 
1. The share of individuals reporting a negative change that we do not observe (= under-reporting) decreases with life satisfaction.

2. The share of individuals reporting a positive change that we do not observe (= over-reporting) increases with life satisfaction.

The figure shows that over-reporting is more common among people with high levels of satisfaction and vice-versa for under-reporting. The information in the graph is somewhat redundant, since the shares of over- and under-reporting sum up to $100 \%$ for each level of life satisfaction, but it illustrates the two steady patterns along the satisfaction scale.

When we extend the analysis to the entire sample, these two patterns persist (Figure 2b ). On the one hand, the share of people declaring a positive change that we do not observe is significantly higher among satisfied respondents than among unsatisfied ones. On the other hand, the share of people declaring a negative change that we do not observe is significantly lower among satisfied respondents than among unsatisfied ones. The share of people reporting no change or a change which is consistent with what we observe in the panel is constant across levels of $L S_{t}$ : around $75 \%$, except for an increase at the upper boundary.

Figure 2: Mis-reporting conditional on life satisfaction

(a) Whether $L S_{i t}=L S_{i t-1}$ and $\Delta \widetilde{L S}_{i t-1} \neq \Delta L S_{i t-1}$

(b) For the entire sample
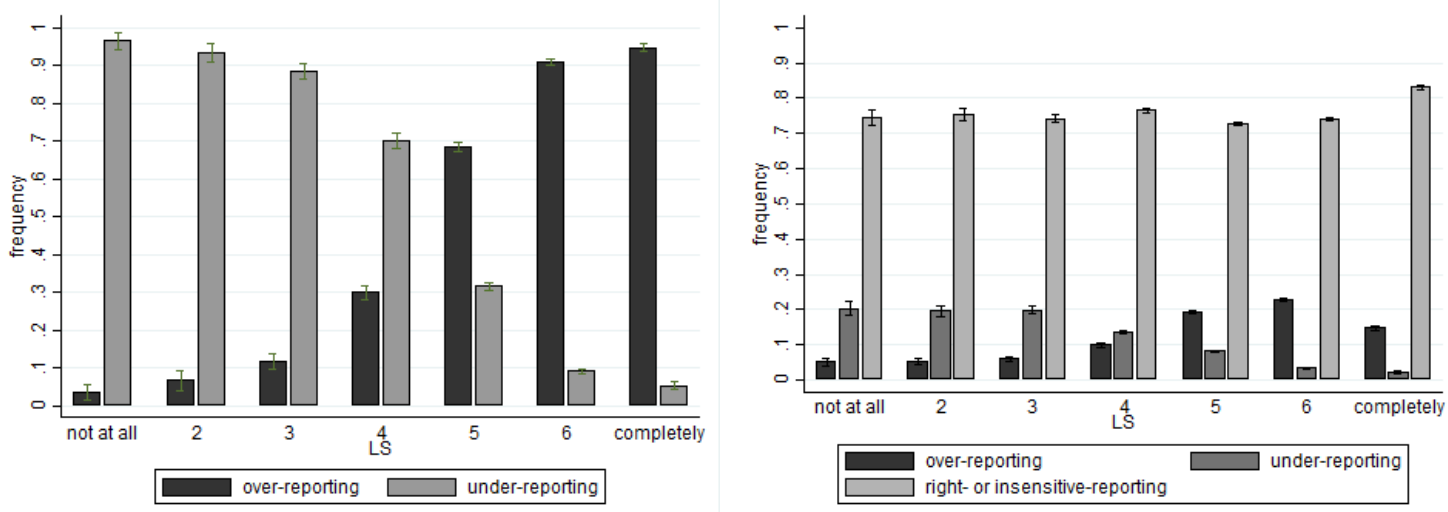

Reading note: share of misreporting conditional on current life satisfaction. Vertical bars are 95\% confidence intervals. Figure (a) refers to people reporting a pos./neg. change while we observe $L S_{i t}=L S_{i t-1}$. Among misreporters who report LS $=6$ in two consecutive years, 91\% report a positive change, 9\% report a negative change. Figure (b) refers to the entire sample. Among people who report $L S=6$ in year , 23\% report a positive change which is not observed, $3 \%$ report a negative change which is not observed.

Figures $2 \mathrm{a}$ and $2 \mathrm{~b}$ suggest that current satisfaction predicts the direction of the report error and lead us to formulate a third stylized fact: 
Stylized fact \#3: More satisfied people tend to overstate the improvement in their life satisfaction; conversely, unsatisfied people tend to understate it.

\subsection{A matter of scale?}

Could these stylized facts simply reflect some measurement errors due to the life satisfaction scale?

The happiness scale is discrete, while latent well-being is not.

People may report a change in life satisfaction because latent satisfaction - which is continuous - varies, but this variation is not captured by the satisfaction scale - which is discrete. This measurement error could explain over- and under-reporting if small changes occur within the range of the same life satisfaction scalepoint. For instance, someone may report her satisfaction to be 5 both in $t$ and $t+1$, when her satisfaction is 5.1 in $t$ and 5.4 in $t+1$. Therefore, she would rightfully report a positive change, but we would wrongly infer over-reporting. However, if we model the marginal change as a random draw from a symmetrical distribution centered on the latent value, we should be equally likely to observe under- and over-reporting. This is not the case, since in average people tend to overstate the improvement in their life satisfaction (stylized fact \#2). Moreover, it is unlikely that this asymmetry is driven by a persistent marginal positive change, as most of the happiness literature rejects the idea that life satisfaction steadily increases over the life cycle. ${ }^{4}$

Therefore, although widespread misreporting might arise from the inability of the scale to capture marginal changes (stylized fact \#1), it cannot explain why over-reporting is relatively more common (stylized fact \#2) nor why it should be associated with the highest part of the current life satisfaction ladder (stylized fact \#3).

Reported change is qualitative, while latent change is not.

A second caveat could be that the amount of well-being variation that is sufficient to report "I am more / less satisfied" is undetermined. Therefore, people may report no change in life satisfaction if they experience a variation which it is not sufficient to answer "I am more/less satisfied with life than a year ago". The sufficient variation that triggers a reported change is likely to be an idiosyncratic threshold that is hard to detect. This phenomenon can explain why insensitive-reporting is relatively common, yet it cannot explain the different shares in under- and over-reporting.

The scale is bounded, while latent well-being is not.

\footnotetext{
${ }^{4}$ The average observed pattern is U-shaped, with a ditch around 50, see for example (Blanchflower and Oswald, 2008; Cheng et al., 2015) .
} 
A third often criticized aspect of the life satisfaction scale is that it is bounded. The argument is generally the following. Someone is living a joyful fulfilling life and reports complete life satisfaction at year $t$; if the following year her latent satisfaction increases, how can she express this improvement ${ }^{5}$ In this case the very satisfied person reports a positive change because her latent satisfaction - which is unbounded - varies, but the satisfaction scale - which is upper-bounded - cannot capture the increase. This hypothesis can explain over-reporting for people who are completely satisfied both in $t$ and $t+1$ and under-reporting for people who are not satisfied at all both in $t$ and $t+1$. However, it cannot explain the overall patterns, which, as illustrated by figure $2 \mathrm{~b}$, are quite stable along the life satisfaction scale, with no spike at the boundaries. If any, we observe a small fall in the share of over-reporting at the top of the scale.

The fact that the scale is bounded might also trigger some response biases. People might display aversion to report extreme values of the scale, so that a person who reports $L S_{t-1}=6$ is somewhat reluctant to declare herself "completely satisfied" with her life in the following year, even if an important positive leap occurred. However, the same counter-arguments apply: the observed patterns go along the whole scale, so that a person declaring $L S_{t}=5$ is more likely to over-report than a person declaring $L S_{t}=4$, who, in turns, is more likely to over-report than a person declaring $L S_{t}=3$, and so on. These values being relatively far from the scale boundaries, aversion to give extreme values of satisfaction cannot explain the observed patterns.

Overall, these arguments point out at three features of the life satisfaction scale which hinder the detection of actual misreporting. However, none of them (nor their combination) can explain our three stylized facts. We now move on to the scrutiny of current happiness as the determinant of the different recall patterns.

\section{Regression analysis}

If happy people recall past well-being differently than unhappy ones, this asymmetry can accommodate the three patterns. Among the discrepancies between observed and recalled well-being (stylized fact \#1), we would observe that, on average, people tend to overstate the improvement in their well-being over time (stylized fact \#2), because relatively happy people - which represent most of the population - tend to overstate the improvement in their life satisfaction (stylized fact \#3). In this section we move to a parametric approach and use regression analysis that take into account the observable characteristics of the respondent.

\footnotetext{
${ }^{5}$ Nota bene: the problem arises only inasmuch as latent satisfaction increases beyond the numerical cap, say from 7 to $7+$, not if life conditions improve. We should carefully distinguish subjective life satisfaction and objective life conditions. People are not asked to evaluate their objective conditions on a scale, but their subjective satisfaction with those conditions. As a consequence, a person who is fully satisfied with her life can keep on being fully satisfied with her life after a positive improvement in her objective life conditions, so that $\Delta \widetilde{L S}_{i t-1}=0$.
} 
This allows to document the relationship between current and recalled happiness ceteris paribus, net of spurious correlations.

\subsection{A model of imperfect recall}

In order to spell out clearly the assumptions underlying our specifications, we start by sketching a model of imperfect recall. Define the following variables:

Today's life satisfaction $=L S_{t}$.

Past life satisfaction $=L S_{t-n}$.

Observed change in life satisfaction $=\Delta L S_{i t-n}=L S_{i t}-L S_{i t-n}$.

Recalled evolution of life satisfaction $=\Delta \widetilde{L S}_{i t-n}$.

Let us express the recalled evolution $\Delta \widetilde{L S}_{i t-n}$ as a function of current and past satisfaction: $f\left(L S_{i t}, L S_{i t-n}\right)$. Our first assumption relies on the additive separability of the recall function $f($.$) , so that the evolution of life$ satisfaction reported today is the difference between today's well-being and recalled past well-being, defined by a function $m($.$) :$

$$
\Delta \widetilde{L S}_{i t-n}=f\left(L S_{i t}, L S_{i t-n}\right)=L S_{i t}-m\left(L S_{i t-n}\right)=L S_{i t}-\widetilde{L S}_{i t-n}
$$

where $\widetilde{L S}_{i t-n}=$ recalled past life satisfaction. ${ }^{6}$ Therefore, we can rewrite $E R R_{i t-n}=\Delta \widetilde{L S}_{i t-n}-\Delta L S_{i t-n}$ as $E R R_{i t-n}=L S_{i t}-\widetilde{L S}_{i t-n}-\left(L S_{i t}-L S_{i t-n}\right)=L S_{i t-n}-\widetilde{L S}_{i t-n}$.

We assume latent current happiness to be perfect information, and $\Delta \widetilde{L S}_{i t-1}$ to be imperfect information, mediated by memory. That is to say, we do not question people's capacity to assess their current wellbeing, but their ability to recall their past well-being. Our second assumption is then that errors in recalled evolution are not random, but biased by an observable variable $Z$ according to a factor $\theta$, a parameter which captures the size and direction of the recall bias. Therefore, we can write the recall function $m($.$) as an$ inter-temporal mapping which defines a distribution of potentially recalled satisfactions, so that:

$$
\widetilde{L S}_{i t-n}=L S_{i t-n}+\theta Z_{i t}+\epsilon, \quad \text { where } \epsilon \sim N\left(0, \sigma_{n}^{2}\right) .
$$

Our third and last assumption involves the functional forms of the parameters: $\sigma_{n}^{2}$ is non-decreasing over $n$ and $\theta$ is weakly monotonic over $n, \forall n$. The intuition behind this specification is that recall precision decays over time and that the effect of $Z$ on recalled well-being never reverts, independently of the temporal distance. This assumption allows for some generality of the recall model.

According to our model, $\widetilde{L S}_{i t-n}$ is a random variable, whose expected value is centered at $L S_{i t-n} \pm$ some bias, and whose variance is defined by the white noise component $\epsilon$. We study the impact of current

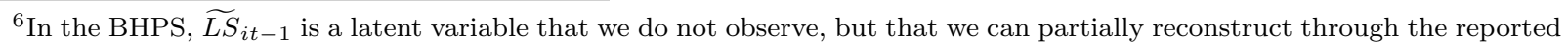
change in life satisfaction.
} 
life satisfaction on recalled past satisfaction, so that $Z_{i t}=L S_{i t}$. Therefore, $E\left[\widetilde{L S}_{i t-n}\right]=L S_{i t-n}+\theta L S_{i t}$ and $\operatorname{var}\left[\widetilde{L S}_{i t-n}\right]=\sigma_{n}^{2}$.

Finally, these definitions are also based on the assumption that the individual life satisfaction scale is stable over time, so that $L S_{i t}$ and $L S_{i t-1}$ are measured on the same scale.

\subsection{Cross-sectional regression analysis}

We estimate a linear satisfaction equation of the form:

$$
L S_{i}=X_{i} \alpha+u_{i}
$$

where $L S_{i}$ is the life satisfaction of individual $i$ in wave $7, u_{i}$ is a normally distributed error term and $X_{i}$ is a matrix of observable characteristics which includes a constant vector, sex, age, age ${ }^{2}$, household income, $\Delta$ income, number of children, civil status, job status, education level, ethnicity and five dummies which take value one if over the past year the person had a baby, moved to widowhood or to unemployment, got married or got divorced.

We carry on a cross-sectional regression by standard OLS and present estimation results in the Appendix, table 6 . This first stage regression allows us to compute the vector of residuals $\hat{u}$, which is orthogonal to the explanatory variables of the model, by construction. We can interpret $\hat{u}_{i}$ as the individual-specific residual life satisfaction, conditional on the observables. Figure 3 illustrates the average residual satisfaction by group of reporting behavior. The uncovered patterns are the same as before: individual idiosyncratic satisfaction is higher for over-reporters and lower for under-reporters, while it is statistically equal to zero for the rest of the sample.

Figure 3: Mean happiness residual, wave 7

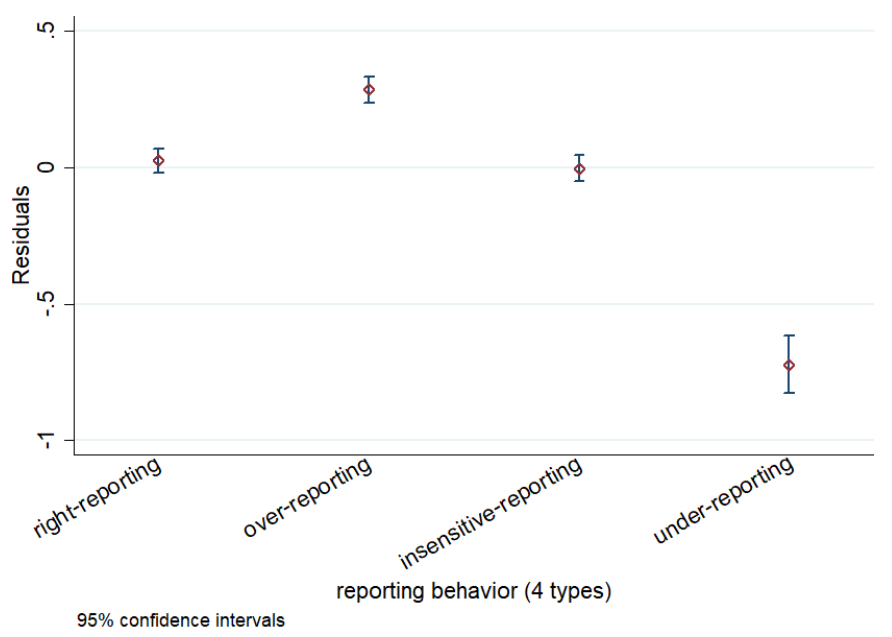




\subsection{Panel regression analysis}

We now move on to the panel dimension. We study the probability to observe a given reporting behavior, conditional on current satisfaction and a set of observables. At first, we restrict the sample to people who declare the same life satisfaction in $t-1$ and $t$. With this restriction $\left(L S_{i t-1}=L S_{i t}\right)$, reporting a positive change corresponds to over-reporting, a null change to correct-reporting and a negative change to underreporting. ${ }^{7}$ Therefore, we study a model where the probability to report a given outcome $j, j=\{$ more satisfied, about the same, less satisfied\}, is determined by current life satisfaction and other covariates, i.e. we estimate $P\left(\widetilde{L S_{i t}}=j \mid L S_{i t} ; X_{i t}\right)$. We estimate the model by Ordered Probit and cluster errors at the individual level to correct for individual-specific error correlation over time.

Table 4 displays regression estimates, with and without controls (columns (1) and (2)). The coefficient associated with life satisfaction is positive and highly statistically significant, meaning that the higher a person's life satisfaction, the higher her probability to over-report and the lower the probability to underreport. The estimated average marginal effect (not displayed in the table) tells us that, on average, one more point in the life satisfaction scale increases the probability to be an over-reporter by $11 \%$ and decreases the probability to be an under-reporter by $6 \%$. A counter-factual example offers an intuition of the magnitude of the effect: among people who declare $L S_{t-1}=L S_{t}$, a 46-year-old female respondent with medium education level has $34 \%$ chances to over-reporter if her life satisfaction is 6 in both years, against less than $5 \%$ if her life satisfaction is 3 in both years (see tab. 5). Figure 5 offers a visual illustration of the concepts contained in the table. Figure (4a) graphically shows the baseline individual's predicted probabilities to over- and underreport for any value of life satisfaction.

Ordered Probit estimates assume the set $j=\{$ more satisfied, about the same, less satisfied $\}$ to be ordered. To relax this assumption, we move to an estimation by Multinomial Logit, where we set again correctreporting as base category. ${ }^{8}$ Results, reported in table 4 (top part, columns (3) to (6)), substantially confirm the positive (resp. negative) conditional correlation between well-being and over-reporting (resp. underreporting). Moreover, the estimation of a more flexible specification, which allows to single out effects at the upper- and lower-bound of the satisfaction scale, shows that these results are not driven by boundary effects

\footnotetext{
${ }^{7}$ It may seem odd to see a specification where memory of a past variable is predicted by current satisfaction. However, the memory of life satisfaction $m\left(L S_{i t-1}\right)$ is occurring at time $t$, so that the predicted variable is contemporary (or subsequent) with respect to the predictors. In this sense, the notation $m_{t}\left(L S_{i t-1}\right)$ would be more precise, but we drop the time index to keep notation relatively light.

${ }^{8}$ Estimation is valid under the IIA assumption, which is very reasonable in our case: odds of reporting "more satisfied" instead of "about the same" does not depend on the alternative "less satisfied" being present or not. Mutatis mutandis for all categories. We should also underline that our model contains only case-specific regressors, that is variables that do not change according to the decision which is made (reporting a pos., neg. or null change). Whether we had alternative-specific variables (let's say one is paid differently according to what she reports), conditional or mixed logit models would be more appropriate.
} 
(see appendix, table 7).

So far we have focused on the exemplary case of people who report the same satisfaction in year $t$ and $t-1$. However, people may misreport even when $L S_{t} \neq L S_{t-1}$. This case allows for insensitive-reporting (people answering "about the same" when $L S_{t} \neq L S_{t-1}$ ) as well as for extreme over- and under-reporting behaviors (people answering "more satisfied" when $L S_{t}<L S_{t-1}$ and "less satisfied" when $L S_{t}>L S_{t-1}$ ).

When we extend the analysis to the entire sample (table 4), results are qualitatively similar: the higher the life satisfaction level, the higher the probability to over-report and the lower the probability to underreport. The table also shows that satisfaction has a small but significant negative effect on the probability to insensitive-report. We estimate the model by Multinomial Logit, since the inclusion of insensitive-reporters does not allow for a natural ordering of the outcomes, required by Ordered Probit models.

Estimated probabilities are listed in table 5 and graphically displayed in figure (4b). Let us take again the example of a 46-year-old female respondent with medium educational level, who reports either $L S=3$ or $L S=6$ at time $t$. In the first case, she has respectively $9 \%$ chances to over-report and $18 \%$ to under-report. In the second case, she has $21 \%$ chances to over-report and $5 \%$ chances to under-report. Regardless of her satisfaction level, her chances to correct-report ( $49 \%$ if $\mathrm{LS}=6,46 \%$ if $\mathrm{LS}=3$ ) or to insensitive-report $(27 \%$ if $\mathrm{LS}=6,25 \%$ if $\mathrm{LS}=3$ ) are virtually constant. ${ }^{9}$

\footnotetext{
${ }^{9}$ To avoid information burden, these predictions are not showed in the graphic, but only in the table.
} 
Figure 4: Predicted probabilities of over- and under-reporting

(a) For $L S_{i t}=L S_{i t-1}$

(Pooled Ordered Probit)

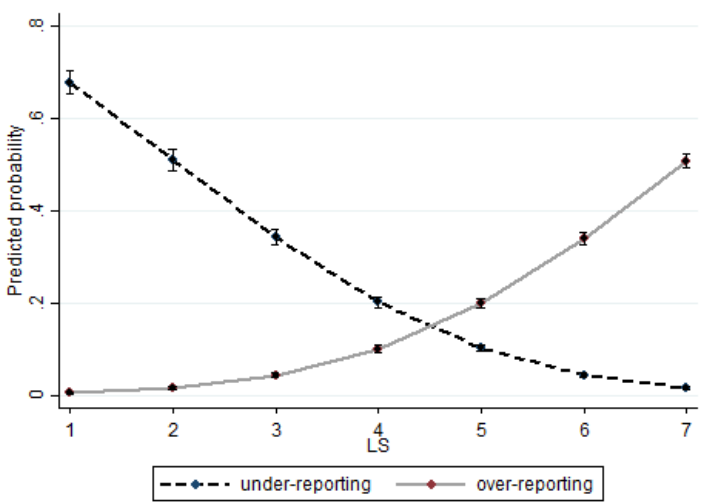

(b) For the whole sample

(Pooled Multinomial Logit)

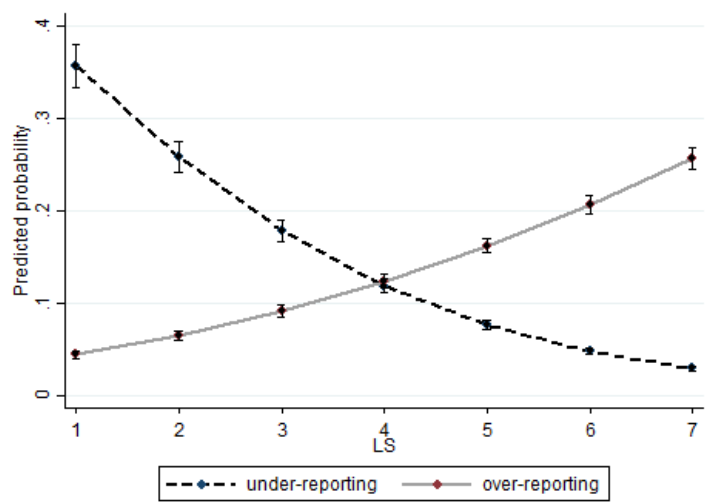

Reading note: predicted probability of over-and under-reporting, estimated for an employed medium-educated married woman, with sample average age and income, without children, who is not Asian/Black. Vertical bars are 95\% confidence intervals. Figure (a) tells that a person with the stated characteristics, who declared the same LS in $t$ and $t-1$, has an estimated probability to over-report of $30 \%$ if $L S=6$, of $4 \%$ if $L S=3$. Figure (b) tells that a person with the stated characteristics, has an estimated probability to over-report of $17 \%$ if $L S=6$, of $8 \%$ if $L S=3$.

Figure 5: Predicted conditional recall probabilities: $P\left(\widetilde{L S} \widetilde{L t-1}_{t} \mid L S_{t}\right)$.

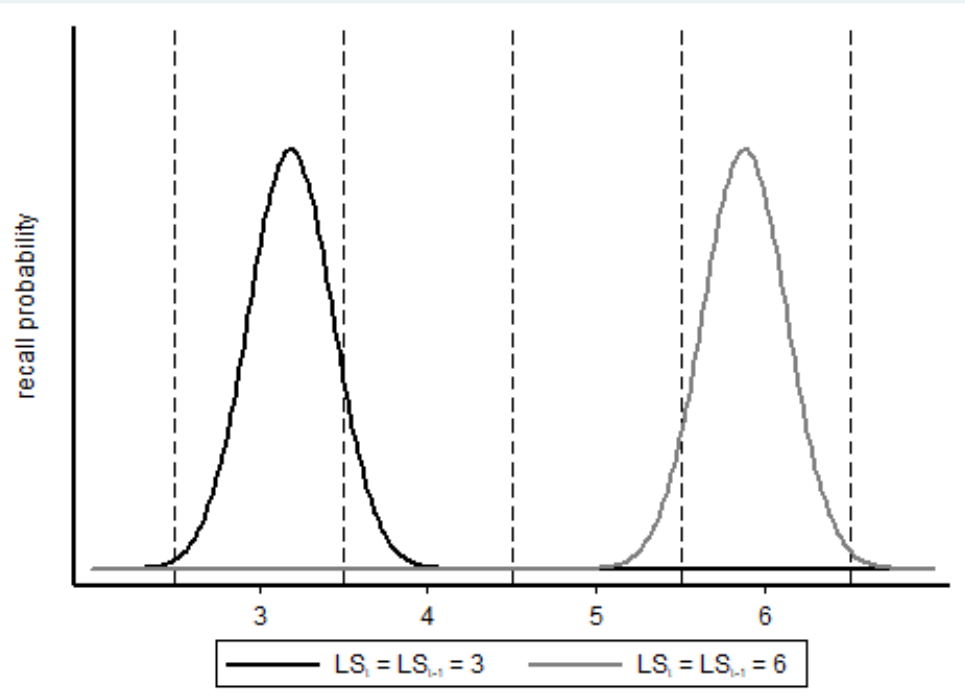

Reading note: Density functions of $m\left(L S_{t-1}\right)$, according to the level of current well-being, for $\sigma^{2}=1$. The black curve represents the probability of a person who reported $L S=3$ two years in a row, to recall past satisfaction as lower (4\%), same (58\%) or higher (38\%). The gray curve represents equivalent information for a person who reported LS =6 two years in a row. 
Table 4: Categorical regression of reporting behavior on life satisfaction.

\begin{tabular}{|c|c|c|c|c|c|c|}
\hline & (1) & $(2)$ & (3) & (4) & (5) & (6) \\
\hline & Ord.Probit & Ord.Probit & Correct-rep. & Over-rep. & Insensitive-rep. & Under-rep. \\
\hline \multicolumn{7}{|c|}{$\Delta L S_{i t-1}=0$} \\
\hline \multirow[t]{2}{*}{$L S_{i t}$} & $0.376^{* * *}$ & $0.431^{* * *}$ & baseline & $0.417^{* * *}$ & 0 & $-0.985^{* * *}$ \\
\hline & $(60.33)$ & $(63.17)$ & & $(24.76)$ & (.) & $(-53.18)$ \\
\hline Controls & & $\checkmark$ & $\checkmark$ & $\checkmark$ & $\checkmark$ & $\checkmark$ \\
\hline $\mathrm{N}$ & 50,450 & 49,274 & 49,274 & 49,274 & 49,274 & 49,274 \\
\hline \multicolumn{7}{|c|}{ Whole sample } \\
\hline \multirow[t]{2}{*}{$L S_{i t}$} & & & baseline & $0.246^{* * *}$ & $-0.0493^{* * *}$ & $-0.464^{* * *}$ \\
\hline & & & & $(26.09)$ & $(-7.43)$ & $(-49.89)$ \\
\hline Controls & & & $\checkmark$ & $\checkmark$ & $\checkmark$ & $\checkmark$ \\
\hline $\mathrm{N}$ & & & 109,074 & 109,074 & 109,074 & 109,074 \\
\hline
\end{tabular}

Reading note: multinomial regressions with clustered errors at the individual level of reporting behaviors on current life satisfaction. The regressand is a categorical variable for reporting behaviors. Columns(1) and (2) refer to two separate Ordered Probit estimations, where the explained variable is coded as follows: over-reporting $=1$, correct-reporting $=0$, under-reporting $=-1$. Columns (3) to (6) refer to a Mulinomial Logit estimation, where correct-reporting is the baseline category. $z$-statistics in parentheses. ${ }^{*} p<0.10,{ }^{* *} p<0.05,{ }^{* * *} p<0.01$. Controls: sex, age, age ${ }^{2}$, log(household income), $\Delta$ income, education level, number of children, marital status, job status and ethnicity and five dummies which take value one if over the past year the person had a baby, moved to widowhood or to unemployment, got married or got divorced. 
Table 5: Estimated probabilities to display a recall behavior

\begin{tabular}{|c|c|c|c|c|}
\hline & (1) & (2) & (3) & (4) \\
\hline & Correct-rep. & Over-rep. & Insensitive-rep. & Under-rep. \\
\hline \multicolumn{5}{|l|}{$\Delta L S_{i t-1}=0$} \\
\hline \multirow[t]{2}{*}{$L S_{i t}=3$} & $0.613^{* * *}$ & $0.044^{* * *}$ & 0 & $0.343^{* * *}$ \\
\hline & $(84.47)$ & $(17.95)$ & (.) & $(36.90)$ \\
\hline \multirow[t]{2}{*}{$L S_{i t}=6$} & $0.615^{* * *}$ & $0.340^{* * *}$ & 0 & $0.045^{* * *}$ \\
\hline & $(117.06)$ & $(52.64)$ & (.) & $(24.68)$ \\
\hline Controls & $\checkmark$ & $\checkmark$ & $\checkmark$ & $\checkmark$ \\
\hline $\mathrm{N}$ & 49,274 & 49,274 & 49,274 & 49,274 \\
\hline \multicolumn{5}{|l|}{ Whole sample } \\
\hline \multirow[t]{2}{*}{$L S_{i t}=3$} & $0.459^{* * *}$ & $0.092^{* * *}$ & $0.271^{* * *}$ & $0.178^{* * *}$ \\
\hline & $(79.45)$ & $(29.48)$ & $(50.20)$ & $(29.63)$ \\
\hline \multirow[t]{2}{*}{$L S_{i t}=6$} & $0.494^{* * *}$ & $0.206^{* * *}$ & $0.252^{* * *}$ & $0.048^{* * *}$ \\
\hline & $(104.33)$ & $(42.33)$ & $(57.78)$ & $(27.49)$ \\
\hline Controls & $\checkmark$ & $\checkmark$ & $\checkmark$ & $\checkmark$ \\
\hline $\mathrm{N}$ & 109,075 & 109,075 & 109,075 & 109,075 \\
\hline
\end{tabular}

Reading note: predicted probability of over- and under-reporting, estimated for an employed medium-educated married woman, with sample average age and income, without children, who is not Asian/Black. Estimation by Ordered Probit on the restricted sample and by Multinomial Logit on the whole sample. Clustered errors at the individual level, base category $=$ correct-reporting. z-statistics in parentheses. ${ }^{*} p<0.10,{ }^{* *} p<0.05,{ }^{* * *} p<0.01$. Controls: sex, age, age ${ }^{2}, \log ($ household income), $\Delta$ income, education level, number of children, marital status, job status, ethnicity and five dummies which take value one if over the past year the person had a baby, moved to widowhood or to unemployment, got married or got divorced. Column (2), first block, tells that a person with the stated characteristics, who declared the same LS in $t$ and $t-1$, has an estimated probability to over-report of $27 \%$ if $L S=6$, of $4 \%$ if $L S=3$. Column (2), second block, tells that a person with the stated characteristics has an estimated probability to over-report of $17 \%$ if $L S=6$, of $8 \%$ if $L S=3$. 


\section{Beyond BHPS: the anatomy of recalled happiness}

Our model is based on a few pivotal assumptions.

1. Recalled satisfaction is additively separable. Under this assumption, a person who reports the evolution of her life satisfaction from a previous period until now is comparing her current satisfaction which is perfect information - with her past satisfaction - which is mediated by memory. Formally, this assumption allows to write $\Delta \widetilde{L S}_{i t-1}=L S_{i t}-\widetilde{L S}_{i t-1}$.

2. The effect of current well-being on memory is monotonic, so that the recall bias is not specific to a particular time lag t. According to this assumption, our results are not driven by proximity of the recalled subjective item, and current well-being biases recalled well-being in the same direction, regardless of the length of the time lag. In other words, people have similar biased recall for both recent and remote happiness.

3. People have an imperfect but meaningful reconstruction of their past well-being over a stable life satisfaction scale. This assumption allows intra-personal comparisons of well-being over time. Formally, it allows to write $\widetilde{L S}_{i t-1}=m\left(L S_{i t-1}\right)$.

BHPS data do not allow to test these assumptions. To test assumption (1), we need to observe the reported past level of well-being $\widetilde{L S}_{i t-1}$, which is not asked in the British survey. Assumption (2) cannot be confirmed without the subjective reconstruction over a longer time span $f\left(L S_{i t}, L S_{i t-n}\right), n>1$. Assumption (3) requires to observe the subjective reconstruction of well-being over multiple periods: $\widetilde{L S}_{i t-1}, \widetilde{L S}{ }_{i t-2}$, etc... To test these assumptions, we move on to the analysis of two additional data sets: the Well-being module of the French Consumer Confidence Survey (CAMME) and the German Socio-Economic Panel (SOEP).

\subsection{Self-declared past happiness}

According to assumption (1), overstating the evolution of well-being implies understating the past level of well-being. To verify this, we use quarterly data drawn from the Enquête de conjoncture auprès des ménages (CAMME), a French monthly consumer confidence survey run by the national statistical office (INSEE). Since June 2016, the survey includes a well-being module, which surveys a representative sample of the French population. Our dataset is a longitudinal series of repeated cross-sections from 18,687 respondents over 11 quarterly waves, from June 2016 to December 2018.

On top of a question about current life satisfaction, the survey also includes a question on the level of satisfaction one year ago. Respondents give an answer on a scale from 0 to 10 to the following questions: "Overall, how satisfied are you with your current living situation?" and "When you think at last year, where would you place yourself on a scale from 0 to 10?". Therefore, this survey allows to observe for the 
same individual $L S_{i t-1}$ and $\widetilde{L S}_{i t-1}$. To be sure, people are not interviewed twice, so that the actual past satisfaction $L S_{i t-1}$ is not available, however, insofar as each sample is representative of the same population, we can compare aggregate data on observed and recalled life satisfaction at the national level. Loosely speaking, we can consider France as an individual and compare its recalled and observed levels of wellbeing at twelve-month distance. Graph 6 contrasts recalled and observed happiness over seven quarters. Consistently with our predictions, at each quarter, the average reported well-being at a point of time is higher than the average well-being recalled for the same period. Differences are statistically significant at $10 \%$ or $5 \%$ for all periods except the first one.

Overall, this observation endorses the interpretation of the stylized facts in terms of differential recall of the past level of satisfactions. It allows to extend stylized fact \#2 with a corollary:

Stylized fact \#2: On average, people tend to overstate the improvement in their life satisfaction over time. Corollary \#2.1: On average, people understate their past happiness.

Figure 6: Average observed and recalled life satisfaction

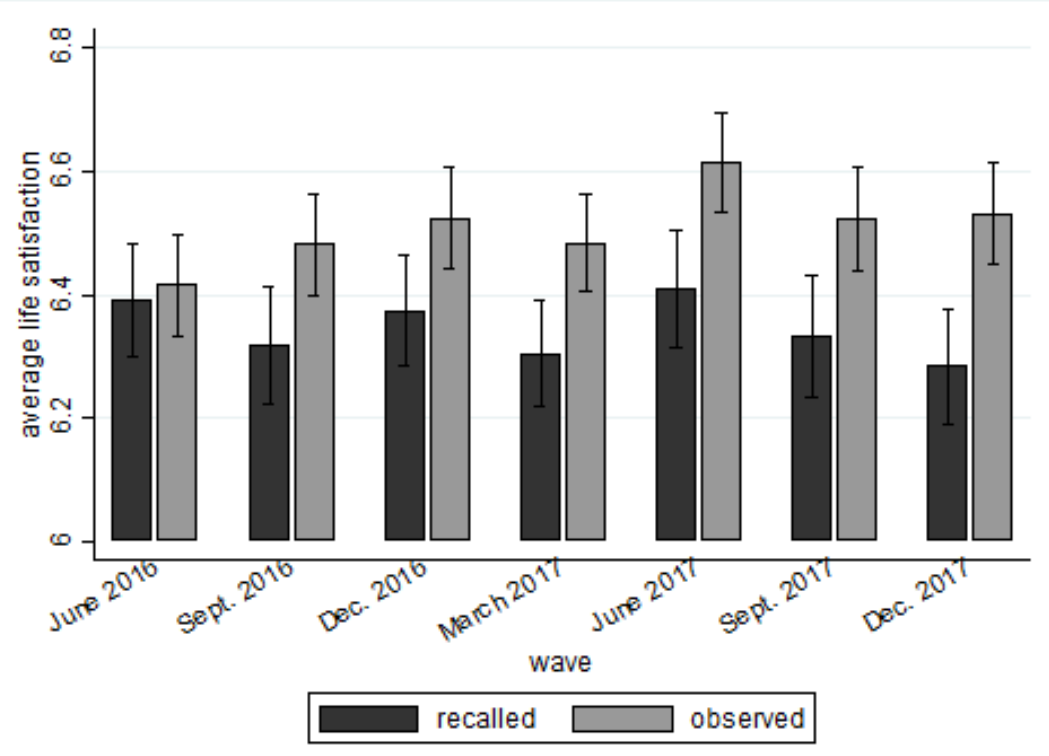

Reading note: The gray bars refer to the average current life satisfaction reported in period $t$. The black bars refer to the average recalled satisfaction reported one year later, in $t+1$. The average life satisfaction in June 2017 is 6.6, while the average recalled life satisfaction for the same period is 6.4 .

Finally, it is worth noting that the second moment of the distribution of recalled satisfaction is higher than the second moment of the distribution of current satisfaction, as predicted by our model of recall described by eq.(2). This and other descriptive statistics of the CAMME dataset are presented in the Appendix, table8. 


\subsection{People have biased recall of both recent and remote happiness}

According to our model of recall bias, the effect is not specific to the memory of recent happiness (i.e. last year), but it applies to memories of more remote happiness too. To enquire, we use the German SocioEconomic Panel (SOEP). In 2016 (wave 33), respondents were asked to reconstruct the pattern of their life satisfaction over the previous ten years. By comparing their answers to the chronicle of their yearly reports of satisfaction, we are able to check whether their subjective reconstructions are consistent. We construct a balanced panel of life satisfaction data from waves 23 to 33, which offers 121,616 individual-year observations, from 11,056 respondents. For some descriptive statistics of the sample, see the Appendix, table9.

In each wave of the survey, respondents are asked to report on a scale from 0 to 10 "How satisfied are you with your life, all things considered?". In 2016, they are asked the following question: "Which of the nine pictures best represents how satisfied you have been with your personal living situation over the last 10 years, so from around 2006 to today?"

Figure 7

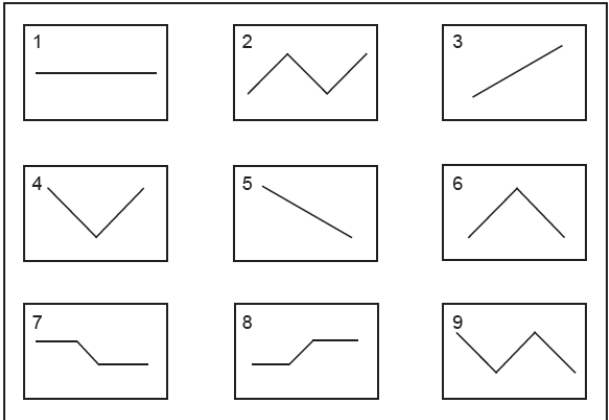

We adopt a strategy akin to the one we used with BHPS and restrict the sample to people who report similar levels of life satisfaction level at ten-year distance, in 2006 and 2016. To preserve a sufficiently large sample (5,993 observations), we allow for a 1-point-discrepancy, so that $L S_{i t} \approx L S_{i t-10}$ if $L S_{i t}=$ $L S_{i t-10} \pm 1 .{ }^{10}$ Then, we compute the average life satisfaction level of people who recall each given pattern over the last 10 years.

Figure 8 shows that people who misreport positive patterns tend to be significantly more satisfied than people who report negative patterns. The figure is akin to figure 1a: it shows how different misreporting behaviors are associated with different average satisfaction. On average, among people who display similar levels of happiness in 2006 and 2016, people who recall a steady positive increase (picture 3) display a satisfaction level higher than 8; those who report a non-linear pattern where $\widetilde{L S}_{i t-10}<L S_{i t}$ (pictures 2 and

\footnotetext{
${ }^{10}$ If we adopt a strict definition and consider only cases when $L S_{i t}=L S_{i t-10}(2,676$ observations), results are qualitatively similar but confidence intervals are sensibly larger.
} 
Figure 8: People who display similar LS in 2006 and 2016: current LS and reconstructed evolution

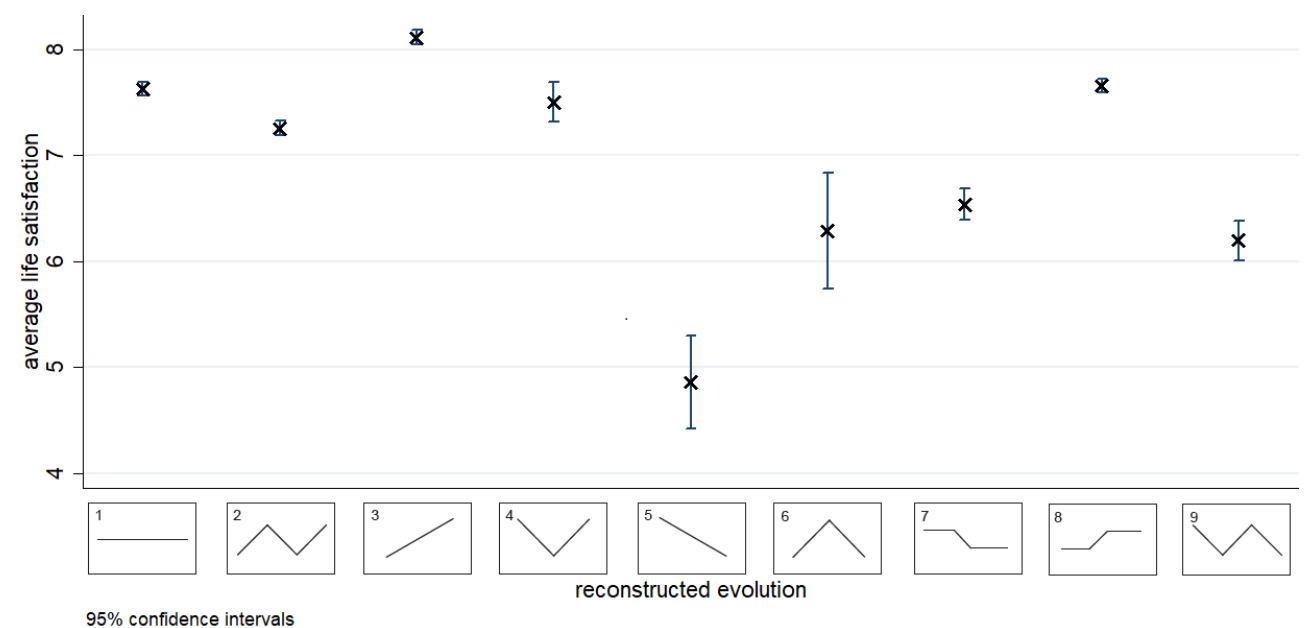

Reading note: The $y$ axis refers to reported life satisfaction, the $x$ axis refers to the picture chosen to represent the evolution of past satisfaction. The figure tells that, among people who display similar levels of happiness in 2006 and 2016 and who choose picture 4 to represent the evolution of their well-being, 7.5 / 10 is the average life satisfaction.

8) report $L S_{i t} \approx 7.5$; those who report a non-linear pattern where $\widetilde{L S}_{i t-10}>L S_{i t}$ (pictures 7 and 9 ) report $L S_{i t} \approx 6.5$; finally, people who recall a steady negative evolution (picture 5) were and are much less satisfied than the rest of the population. In a nutshell, these results extend our former results to a longer time span: Stylized fact \#3: More satisfied people tend to overstate the improvement in their life satisfaction; conversely, unsatisfied people tend to understate it.

Corollary \#3.1: This holds for the recall of both recent and remote happiness.

\subsection{People remember correctly the global evolution of their happiness}

Assumption (3) implies that people are able to map past well-being over the same life satisfaction scale as today. This is crucial, because if there were no correspondence between recalled well-being and observed past well-being, this would mean that either people cannot (even imperfectly) recall how happy they were in the past, or that the life satisfaction scale fully adapts over time, which would hinder any meaningful inference from longitudinal data. Our analysis of BHPS data as well as studies on the test-retest reliability of the subjective well-being scales (Atkinson, 1982; Michalos and Kahlke, 2010) offer limited evidence in support of assumption (3). A more crucial test requires to compare the recalled and observed evolution of well-being over multiple points in time.

The answers from the SOEP survey provide us with a (noisy) measure of recalled well-being over ten years: $\widetilde{L S}_{i t-1}, \widetilde{L S}_{i t-2}, \ldots \widetilde{L S}_{i t-10}$. At the individual level, the measure is quite approximate, since the choice 
of patterns is relatively limited and the timing of the turning points is idiosyncratic. ${ }^{11}$ However, at the aggregate level, discrepancies should cancel out so that the comparison of the average observed evolution of life satisfaction among people choosing a given figure represent a reliable test for assumption (3).

Figure 9 illustrates conditional average observed patterns and compare them to the schematic representation that was chosen by respondents. It turns out that the over 11,000 reported and observed patterns are quite close, in particular when they are monotonic (pictures 1, 3, 5, 7 and 8). When considering the difficulty of the cognitive task at stake - namely, recalling the evolution of a subjective state over a period as long as ten years - the consistency observed in figure 9 is not trivial. It solidly corroborates the idea that people can actually recall - to some extent - their past happiness. It also offers strong supporting evidence for the stability of the satisfaction scale, a pivotal assumption needed by any longitudinal study on subjective well-being. Hence, we can complement our first stylized fact with a reassuring note:

Stylized fact \#1: Most people report an evolution of life satisfaction which is different from the one observed over time in the panel.

Corollary \#1.1: People can, to some extent, recall their past happiness.

\footnotetext{
${ }^{11}$ For instance, a check-mark-type evolution $[\checkmark]$ would correspond more closely to figure 4 , but the turning point is undetermined... and figure 2 would not be an illogical choice either.
} 
Figure 9: Observed evolution of life satisfaction, conditional on the recalled pattern.
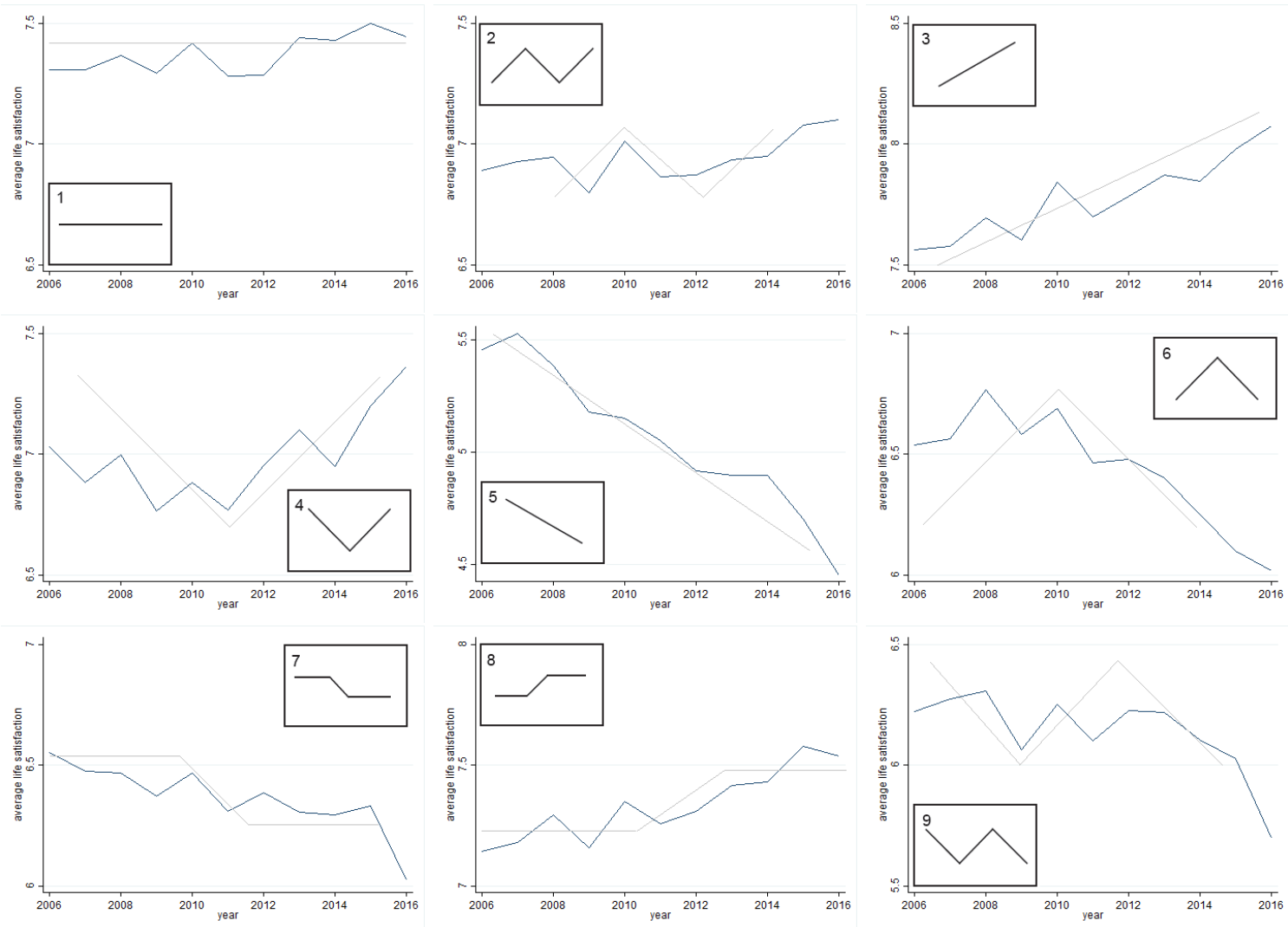

Reading note: The $y$ axis changes from one figure to the other, yet the scale is the same (1 scale point). 


\section{Conclusions}

People's remembered well-being seems to be influenced by their current level of life satisfaction. While happy people tend to overstate the positive evolution of their life satisfaction, unhappy ones tend to exaggerate its worsening. The asymmetric biases that we uncovered cannot be explained by the limits of the measurement tool that we use, i.e. happiness scales. Rather, they seem to derive from purely behavioral factors.

Uncovering the precise cognitive mechanism underlying the biases is beyond the scope of this study. However, here we simply mention two types of theories that are consistent with the observed outcomes. Both are based on the assumption of intra-individual uncertainty, i.e. uncertainty about one's personality features or uncertainty about one's past.

The first one encompasses the psychological mechanisms of strategic self-enhancement. In order to produce a positive self-image, people may distort the memory of their past. Positive delusion, for instance, leads happy people to picture themselves as being on a (pleasant) ascending trajectory, while unhappy ones tend to minimize their past misfortune in order to avoid reinforcing a miserable self-image. As documented by Wilson and Ross $(2000,2001)$, participants in experiments are more critical of distant past selves than of current selves, even when concurrent evaluations indicate no actual improvement. Individuals are also more likely to derogate psychologically distant past selves on attributes that they judge to be important. Finally, they also perceived greater improvement for self than for acquaintances and siblings over the same time period. This structure of temporal appraisal is generally attributed to a self-enhancement process. "Comparisons with inferior past selves may [...] cause individuals to feel good about their present standing on an attribute". Such downward temporal comparisons to past selves are gratifying because "they have the additional benefit of leading people to perceive themselves as improving over time [...] People tend to prefer an improving trajectory" (Wilson and Ross, 2000, p.929). ${ }^{12}$ The illusory "dynamic overstatement" that we uncovered could thus be a self-serving illusion of improving trajectory enacted by happy people. Conversely, self-serving belief manipulation could push unhappy people to overstate their past situation, in an attempt not to see themselves as being in a permanent situation of failure.

A different line of interpretation starts from the idea that people are uncertain about their past happiness. When trying to remember about it, they could act in a Bayesian way, i.e. they proceed as if they were regressing their past happiness towards the mean happiness level of a relevant sample. The latter could be either the mean value of their own happiness over time, or the mean value of their reference group's happiness.

\footnotetext{
${ }^{12}$ The tendency to self-enhancement is articulated with another feature: the preference for improving sequences, which has been theorized and illustrated empirically by Frank and Hutchens (1993), Caplin and Leahy (2001) as well as by Loewenstein and his co-authors (Loewenstein, 1987; Loewenstein and Prelec, 1991; Loewenstein and Sicherman, 1991; Loewenstein, 2006; Camerer et al., 2004).
} 
For instance, in the second case - of inter-personal Bayesian update - the implicit reasoning would be, for a relatively unhappy person: "it is unlikely that I was so much less happy than my reference group", and for a relatively happy person: "it is unlikely that I was so much happier than my peers". ${ }^{13}$ However, in both cases, the update requires a perfect knowledge of the mean happiness level of their reference group, which is a strong assumption. ${ }^{14}$

This paper does not take a stand about the possible cognitive interpretations of its findings, which clearly point to the confusion between levels and variations of happiness. Existing behavioral theories of subjective well-being have abundantly showed that differences and gaps often matter more to individual happiness than absolute levels (of income for instance). Here, we document another type of confusion between levels and variations. We uncover the influence that flows from a person's level of happiness to her remembered past happiness, and the dynamic evolution thereof. Such confusion bears important consequences. In particular, it implies that people's choices and decisions might be biased by wrong memories of their past choices' outcomes. Such misperceptions, in turn, are likely to be at the origin of self-reinforcing spirals of optimism (for happy people) and pessimism (for unhappy ones), giving way to divergent patterns of behavior (e.g. openness to experience) by these groups of the population. Exploring this conjecture is beyond the scope of this study, but is obviously a promising avenue for research.

\footnotetext{
${ }^{13}$ If people rely instead on their recalled happiness associated to past episodes, respondents who tend to experience positive events more often than negative ones could overstate the improvement of their lives over time, and conversely for people who are more subject to negative events (see Wilson et al., 2003; Smith et al., 2008).

${ }^{14}$ Indeed, people are required to know either their average remembered utility - which is at odds with the Peak-End rule (Kahneman et al., 1993) - or the population's average happiness - which is at odds with evidence of social misperception (86\% of people think to be more happy and contented than about 2/3 of the population, see Lykken and Tellegen, 1996).
} 


\section{Appendix}

Table 6: Life satisfaction linear regression, first step

\begin{tabular}{|c|c|}
\hline & OLS \\
\hline \multirow[t]{2}{*}{ age } & $-0.0176^{* * *}$ \\
\hline & $(-2.66)$ \\
\hline \multirow[t]{2}{*}{$\operatorname{age}^{2}$} & $0.201^{* * *}$ \\
\hline & $(2.85)$ \\
\hline \multirow[t]{2}{*}{$\log ($ income $)$} & $0.105^{* * *}$ \\
\hline & $(4.00)$ \\
\hline \multirow[t]{2}{*}{ \# of children in household } & $-0.0857^{* * *}$ \\
\hline & $(-4.01)$ \\
\hline \multirow[t]{2}{*}{ separated } & $-0.735^{* * *}$ \\
\hline & $(-5.74)$ \\
\hline \multirow[t]{2}{*}{ divorced } & $-0.410^{* * *}$ \\
\hline & $(-5.62)$ \\
\hline \multirow[t]{2}{*}{ widowed } & $-0.200^{* *}$ \\
\hline & $(-2.44)$ \\
\hline \multirow[t]{2}{*}{ never married } & $-0.182^{* * *}$ \\
\hline & $(-3.30)$ \\
\hline \multirow[t]{2}{*}{ unemployed } & $-0.555^{* * *}$ \\
\hline & $(-3.92)$ \\
\hline \multirow[t]{2}{*}{ retired } & $0.220^{* * *}$ \\
\hline & $(2.86)$ \\
\hline \multirow[t]{2}{*}{ female } & -0.0283 \\
\hline & $(-0.88)$ \\
\hline \multirow[t]{2}{*}{ constant } & $4.965^{* * *}$ \\
\hline & $(19.15)$ \\
\hline $\mathrm{N}$ & 7,816 \\
\hline
\end{tabular}

Reading note: OLS regression of life satisfaction on observables. $t$-statistics in parentheses. ${ }^{*} p<0.10,{ }^{* *} p<0.05,{ }^{* * *}$

$p<0.01$. Additional regressors not showed in the table are: $\Delta$ income, education level, job status, ethnicity and five additional dummies which take value one if over the past year the person had a baby, moved to widowhood or to unemployment, got married or got divorced. 
Alternative specifications and assumptions

Table 7: Regression of reported evolution on life satisfaction, non-linear effect.

\begin{tabular}{lcc}
\hline \hline & $(1)$ & $(2)$ \\
& Ord.Probit & Ord.Probit \\
\hline$L S_{i t}=1$ & $-1.110^{* * *}$ & $-1.035^{* * *}$ \\
& $(-14.87)$ & $(-12.32)$ \\
$L S_{i t}=2$ & $-1.093^{* * *}$ & $-1.108^{* * *}$ \\
& $(-12.97)$ & $(-12.47)$ \\
$L S_{i t}=3$ & $-0.635^{* * *}$ & $-0.642^{* * *}$ \\
& $(-15.59)$ & $(-14.86)$ \\
$L S_{i t}=5$ & $0.619^{* * *}$ & $0.622^{* * *}$ \\
& $(27.18)$ & $(26.08)$ \\
$L S_{i t}=6$ & $0.976^{* * *}$ & $1.028^{* * *}$ \\
& $(43.98)$ & $(43.99)$ \\
$L S_{i t}=7$ & $0.913^{* * *}$ & $1.168^{* * *}$ \\
& $(35.59)$ & $(43.54)$ \\
$\mathrm{controls}$ & & $\checkmark$ \\
\hline $\mathrm{N}$ & 50,450 & 49,274 \\
\hline \hline
\end{tabular}

Reading note: Ordered Probit regressions with clustered errors at the individual level of reported change in life satisfaction on current life satisfaction. $z$-statistics in parentheses. $L S_{i t}=4$ is the reference category. ${ }^{*} p<0.10,{ }^{* *} p<0.05,{ }^{* * *} p<0.01$. Controls: sex, age, age ${ }^{2}, \log ($ household income), $\Delta$ income, education level, number of children, marital status, job status, ethnicity and five dummies which take value one if over the past year the person had a baby, moved to widowhood or to unemployment, got married or got divorced.

Our main specification assumes the effect of satisfaction on behavior to be linear, a simplifying assumption which may be undue. In addition, this assumption does not allow to disentangle the part of the effect that is associated with the boundaries of the life satisfaction scale from the effect which is associated with the rest of the distribution. To allow for non-linear effects and to single out effects at the upper- and lower-bound, we estimate the model using binary indicators for the different levels of satisfaction. The baseline is the middle of the life satisfaction scale, LS=4. Results are presented in table 7.

The negative sign of coefficients associated with $\mathrm{LS}=2$ and $\mathrm{LS}=3$ means that, everything else being equal, respondents with low levels of satisfaction are less likely to over-report and more likely to under-report than someone with $\mathrm{LS}=4$. The positive sign associated with coefficients $\mathrm{LS}=5$ and $\mathrm{LS}=6$ means that, everything else being equal, respondents with high levels of satisfaction are more likely to over-report and less likely to under-report than someone with $\mathrm{LS}=4$. We abstain from interpreting the estimated coefficients for $\mathrm{LS}=1$ and $\mathrm{LS}=7$, since in this case we cannot disentangle the part of misreporting due to scale boundaries from the one due to $m\left(L S_{i t-1}\right)$. 
Summary statistics of SOEP and CAMME data sets

Table 8: CAMME. Summary statistics.

\begin{tabular}{lccccc}
\hline \hline & mean & se & sd & min & $\max$ \\
\hline life satisfaction & 6.48 & 0.01 & 1.73 & 0 & 10 \\
life satisfaction last year & 6.34 & 0.01 & 1.90 & 0 & 10 \\
female & 0.54 & $<0.01$ & 0.50 & 0 & 1 \\
age & 58.09 & 0.12 & 15.87 & 17 & 101 \\
\hline \hline
\end{tabular}

Reading note: $N=18,435$. The estimated mean life satisfaction in the sample is 6.48. The standard error of the survey-weight estimated mean is 0.01. The empirical standard deviation of the distribution is 1.73 , with values ranging from 0 to 10

Table 9: SOEP. Summary statistics.

\begin{tabular}{lccccc}
\hline \hline & mean & se & $\mathrm{sd}$ & $\min$ & $\max$ \\
\hline life satisfaction & 7.15 & 0.06 & 1.71 & 0 & 10 \\
female & 0.53 & $<0.01$ & 0.50 & 0 & 1 \\
age & 52.56 & 0.82 & 16.15 & 16 & 105 \\
"Which of the nine pictures...?" & & & \\
picture 1 & 0.28 & $<0.01$ & 0.45 & 0 & 1 \\
picture 2 & 0.24 & $<0.01$ & 0.43 & 0 & 1 \\
picture 3 & 0.13 & $<0.01$ & 0.33 & 0 & 1 \\
picture 4 & 0.03 & $<0.01$ & 0.18 & 0 & 1 \\
picture 5 & 0.03 & $<0.01$ & 0.16 & 0 & 1 \\
picture 6 & 0.01 & $<0.01$ & 0.11 & 0 & 1 \\
picture 7 & 0.07 & $<0.01$ & 0.25 & 0 & 1 \\
picture 8 & 0.15 & $<0.01$ & 0.36 & 0 & 1 \\
picture 9 & 0.06 & $<0.01$ & 0.24 & 0 & 1 \\
\hline \hline
\end{tabular}

Reading note: $N=118,434$ for the socio-demographic statistics and $N=9,126$ for the question on the evolution of life satisfaction. $28 \%$ of the respondents reported picture 1 (see fig.7) to best describe the evolution of their life over the previous 10 years. The standard error of the survey-weight estimated mean is smaller than 0.01. The empirical standard deviation of the distribution is 0.45 , with values ranging from 0 (= not choosing picture 1) to 1 (= choosing picture 1 ). 


\section{References}

Atkinson, T. (1982). The stability and validity of quality of life measures, Social Indicators Research 10(2): 113-132.

Blanchflower, D. G. and Oswald, A. J. (2008). Is well-being U-shaped over the life cycle?, Social Science 83 Medicine 66(8): 1733-1749.

Camerer, C. F., Loewenstein, G. and Rabin, M. (2004). Advances in behavioral economics, Princeton university press.

Caplin, A. and Leahy, J. (2001). Psychological expected utility theory and anticipatory feelings, The Quarterly Journal of Economics 116(1): 55-79.

Cheng, T. C., Powdthavee, N. and Oswald, A. J. (2015). Longitudinal evidence for a midlife nadir in human well-being: Results from four data sets, The Economic Journal 127(599): 126-142.

Clark, A. E. (1999). Are wages habit-forming? Evidence from micro data, Journal of Economic Behavior $\mathcal{E}$ Organization 39(2): 179-200.

Easterlin, R. A. (2001). Income and happiness: Towards a unified theory, The economic journal 111(473): 465-484.

Foster, G., Frijters, P. and Johnston, D. W. (2012). The triumph of hope over disappointment: A note on the utility value of good health expectations, Journal of Economic Psychology 33(1): 206-214.

Frank, R. H. and Hutchens, R. M. (1993). Wages, seniority, and the demand for rising consumption profiles, Journal of Economic Behavior \&3 Organization 21(3): 251-276.

Furnham, A. and Petrides, K. (2003). Trait emotional intelligence and happiness, Social Behavior and Personality: an International Journal 31(8): 815-823.

Johnson, E. J. and Tversky, A. (1983). Affect, generalization, and the perception of risk, Journal of Personality and Social Psychology 45(1): 20.

Kahneman, D., Fredrickson, B. L., Schreiber, C. A. and Redelmeier, D. A. (1993). When more pain is preferred to less: Adding a better end, Psychological Science 4(6): 401-405.

Kahneman, D., Wakker, P. P. and Sarin, R. (1997). Back to Bentham? Explorations of experienced utility, The Quarterly Journal of Economics 112(2): 375-406.

Loewenstein, G. (1987). Anticipation and the valuation of delayed consumption, The Economic Journal 97(387): 666-684. 
Loewenstein, G. (2006). The pleasures and pains of information, Science 312(5774): 704-706.

Loewenstein, G. and Prelec, D. (1991). Negative time preference, The American Economic Review 81(2): $347-352$.

Loewenstein, G. and Sicherman, N. (1991). Do workers prefer increasing wage profiles?, Journal of Labor Economics 9(1): 67-84.

Lykken, D. and Tellegen, A. (1996). Happiness is a stochastic phenomenon, Psychological Science 7(3): 186189.

Michalos, A. C. and Kahlke, P. M. (2010). Stability and sensitivity in perceived quality of life measures: Some panel results, Social Indicators Research 98(3): 403-434.

Senik, C. (2009). Direct evidence on income comparisons and their welfare effects, Journal of Economic Behavior \& Organization 72(1): 408-424.

Smith, D., Loewenstein, G., Jepson, C., Jankovich, A., Feldman, H. and Ubel, P. (2008). Mispredicting and misremembering: patients with renal failure overestimate improvements in quality of life after a kidney transplant., Health Psychology 27(5): 653.

Steffel, M. and Oppenheimer, D. M. (2009). Happy by what standard? The role of interpersonal and intrapersonal comparisons in ratings of happiness, Social Indicators Research 92(1): 69-79.

Van Praag, B. M. and Ferrer-i Carbonell, A. (2004). Happiness quantified: A satisfaction calculus approach, Oxford University Press.

Wilson, A. E. and Ross, M. (2000). The frequency of temporal-self and social comparisons in people's personal appraisals., Journal of Personality and Social Psychology 78(5): 928.

Wilson, A. E. and Ross, M. (2001). From chump to champ: people's appraisals of their earlier and present selves., Journal of Personality and Social Psychology 80(4): 572.

Wilson, T. D., Meyers, J. and Gilbert, D. T. (2003). "How happy was I, anyway?" A retrospective impact bias, Social Cognition 21(6): 421-446. 